\title{
PAPERS
}

\section{The role of smoking and alcohol in metaplasia and cancer risk in Barrett's columnar lined oesophagus}

\author{
M R Gray, R J Donnelly, A N Kingsnorth
}

\begin{abstract}
Smoking and alcohol consumption predispose to oesophageal mucosal damage and exacerbates gastro-oesophageal reflux. The alcohol and smoking habits of patients with severe oesophagitis $(n=24)$, Barrett's columnar lined oesophagus (CLO) $(n=58)$, and adenocarcinoma arising in CLO $(n=23)$ were studied. There was no significant difference between the age (median 67, 64, and 65 years respectively) or duration of symptoms (median 10 years) in each group. Patients with benign CLO were significantly more likely to be nonsmokers and non-drinkers, or both than patients with both severe oesophagitis and adenocarcinoma $(p<0.001)$. Of those who smoked or drank, patients with CLO had a smoking history of a median 15 pack years (range 2-60 pack years), which was less than both the severe oesophagitis (median $45 \cdot 5$, range 5-150 pack years) $(p<0.01)$, and adenocarcinoma groups (median 55.25, range 4-200 pack years $)(\mathbf{p}<0.001)$. Patients with adenocarcinoma had smoked for more years in total (median 38.5, range 4-54 years) than patients with CLO (median 29.5, range 6-55 years) $(p<0.01)$. Patients with severe oesophagitis (median 38.5, range 27-55 years) and adenocarcinoma patients had a similar long history of smoking both of which were greater than CLO patients $(p<0 \cdot 003)$. Half of the severe oesophagitis group drank more than 40 units/ week and six more than 100 units/week (median 40, range 1->100 units/week), whereas CLO patients who drank did so more moderately (median 10, 1-100 units/week) $(\mathbf{p}<0.02)$. Adenocarcinoma patients also had a somewhat greater alcohol intake than CLO patients, median 15 (1-100 units/week) $(p<0.02)$. Smoking and alcohol consumption do not predispose to the development of metaplastic columnar lined oesophagus in patients with severe gastro-oesophageal reflux but are strongly associated with the development of adenocarcinoma in patients with established Barrett's oesophagus.

(Gut 1993; 34: 727-731)
\end{abstract}

The recognition of Barrett's columnar lined oesophagus (CLO) ${ }^{1}$ is important because of the well established association with the development of dysplasia and adenocarcinoma. ${ }^{23}$ Endoscopic surveys suggest that $10-15 \%$ of patients with symptomatic reflux will be found to have
CLO. ${ }^{4}$ Most cases of adenocarcinoma of the oesophagus can be shown to arise in CLO that is already present and the incidence of adenocarcinoma of the oesophagus is rising. ${ }^{5-7}$

The factors that initiate changes of an adenocarcinoma nature in CLO are unknown. Smoking is known to be an important risk factor for development of squamous carcinomas of the oesophagus in the Western world ${ }^{8}$ and thus could be a likely candidate for adenocarcinomatous change. Also an association with smoking and oesophageal adenocarcinoma has been noted. Smoking has been implicated in the development of CLO in itself ${ }^{10}$ " and the association with cancers arising in CLO could be explained on the basis of induction of oesophageal columnar metaplasia rather than transformation from metaplasia to neoplasia. Consumption of alcohol is often closely linked with smoking.

CLO develops in a background of severe reflux and continous acid exposure of the ulcerated lower oesophagus as shown in animal models. ${ }^{1213}$ Smoking exacerbates gastrooesophageal reflux by reducing lower oesophageal sphincter pressure ${ }^{14-16}$ and increasing the frequency of gastro-oesophageal reflux episodes, ${ }^{17}$ reducing oesophageal acid clearance, ${ }^{18}$ increasing gastric acid secretion, ${ }^{19}$ and duodenogastric reflux. ${ }^{20-22}$ Smoking may prevent healing of oesophagitis by reducing salivary epidermal growth factor secretion ${ }^{23}$ and reduces the rate of healing in response to anti-reflux medication. ${ }^{24}$

This study aims to assess the role of smoking and alcohol in the development of adenocarcinoma in CLO and to distinguish its role as a carcinogen from its possible role in the pathogenesis of Barrett's oesophagus.

Patients and methods

Three groups of patients were studied: patients with CLO $(n=58)$, median age 64 (range 31-83) sex ratio 3:1 male to female. Patients with adenocarcinoma arising in CLO $(n=23)$, median age 65 (range 52-82), sex ratio 7:1 male to female. Patients with severe reflux oesophagitis $(n=24)$, median age 67 , sex ratio $3: 1$ male to female.

Patients with CLO who were under surveillance were identified on the Royal Liverpool Hospital and Broadgreen Hospital endoscopy unit computers. The diagnosis was confirmed at endoscopy and biopsy specimens taken. Patients with less than $5 \mathrm{~cm}$ of CLO 
Figure 1: Duration of symptoms of gastrooesophageal reflux.

Figure 2: Total pack years (years smoked $\times$ packs/day) smoked.

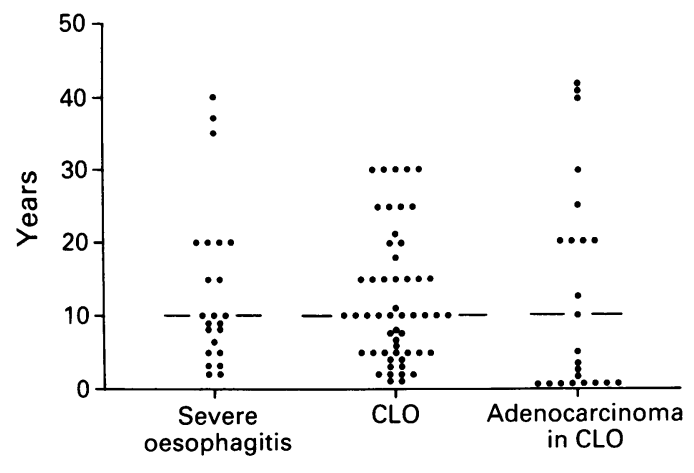

proximal to the gastro-oesophageal junction defined by endoscope within the tubular oesophagus were excluded.

Adenocarcinoma arising in CLO was defined as either: (1) Adenocarcinoma of the oesophagus arising in patients with CLO already present; (2) Adenocarcinoma of the oesophagus confined solely to the oesophagus and associated with specialised type metaplastic CLO; (3) Adenocarcinoma in situ in Barrett's oesophagus requiring oesophagectomy. Patients with adenocarcinoma in CLO were identified at follow up of

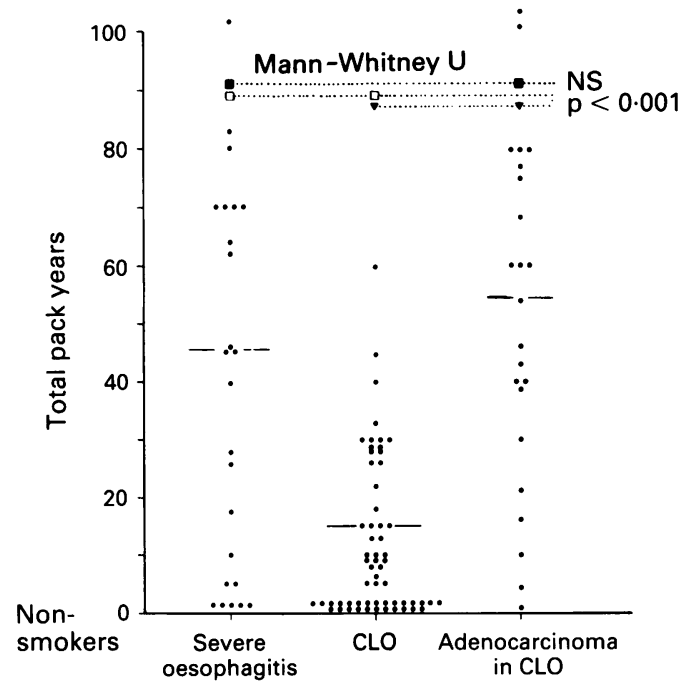

Figure 3: Total duration of smoking in years.

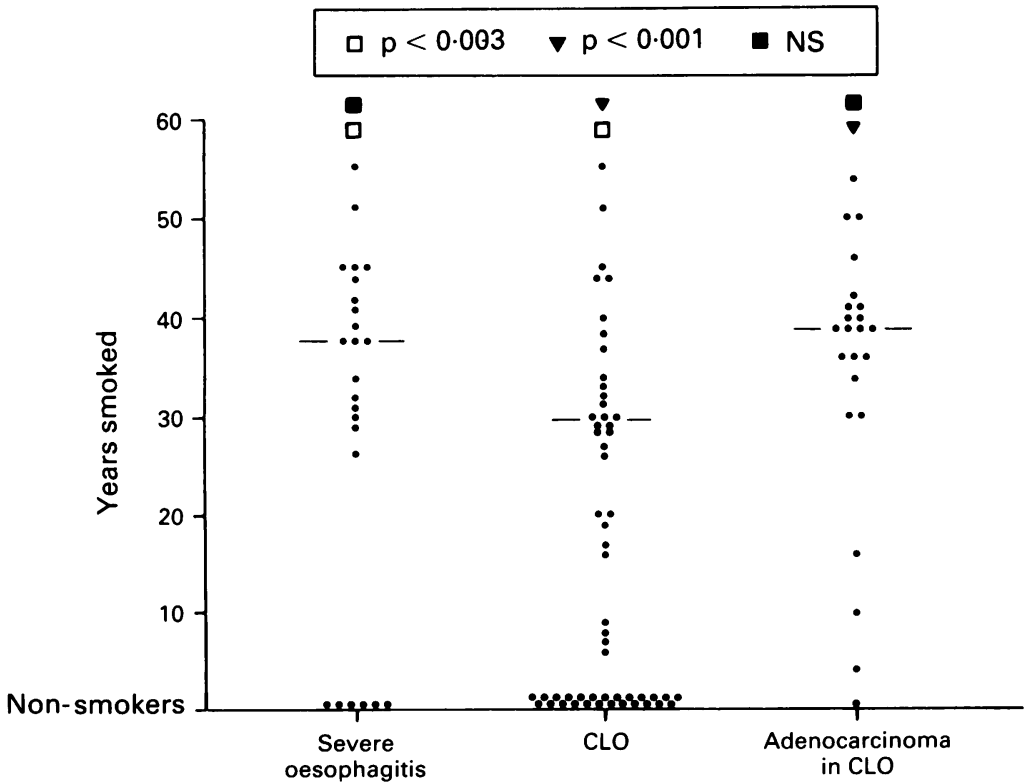

existing CLO or presented de novo to the surgeons and gastroenterologists of the hospitals taking part in the study. The Cardiothoracic Centre Liverpool is a regional referral centre.

Severe reflux oesophagitis was defined as circumferential ulceration of the oesophagus in association with stricturing. Patients with this condition occurring within three years of the date of the study were identified and those still under the care of the endoscopy service were recalled. Biopsy evidence of the absence of metaplastic columnar epithelium was obtained in all cases, however, because of the need to perform an additional endoscopy entry into the study was in the order of $60 \%$ of those contacted.

Patients were questioned on the duration of symptoms and their current and past smoking histories: age of starting smoking, cigarettes per day and years of abstinence, and regular alcohol intake. A pack year was defined as $\mathbf{2 0}$ cigarettes per day smoked for one year. A unit of alcohol was defined as a half a pint of beer or one sixth of a gill of spirits.

All data were collected using a standardised face to face interview by one of the authors (MRG) in the endoscopy unit or on the ward. All statistics were calculated using the ARCUS Professional statistics package. Mann Whitney U non-parametric analysis was used throughout other than where stated. Results are expressed as median and range.

\section{Results}

AGE, SEX, AND DURATION OF HISTORY

There was no significant difference between the age of the groups (median 64, 65, and 67 respectively) or the length of their reflux history (median 10 years in each group) (Fig 1). The sex ratio of the CLO and severe oesophagitis groups was similar ( 3 males: 1 female) but there was an excess of males in the adenocarcinoma group ( 7 males: 1 female). Only one patient was nonwhite. Previous gastric surgery was uncommon in all three groups and showed no significant difference.

\section{SMOKING HISTORY}

A significant proportion of patients with CLO had never smoked (24 of 58); non-smokers were significantly less common in the severe reflux oesophagitis (6 of 24) and adenocarcinoma groups (1 of 23) $\left(\mathrm{p}<0.001 \chi^{2}\right)($ Fig 2$)$.

Of those who smoked, patients with CLO had a median smoking history of 15 pack years (range 2-60 pack years) which was less than both the severe oesophagitis (median 45.5, range 5-150 pack years; $\mathrm{p}<0.001$ ) and adenocarcinoma groups (median $55 \cdot 25$, range $4-200$ pack years) $(\mathrm{p}<0.001)$ (Fig 2). Severe oesophagitis patients (median 38.5, range 27-55 years) and adenocarcinoma patients had similar long histories of smoking, both of which were greater than CLO patients $(\mathrm{p}<0.003)$ (Fig 3).

Patients with adenocarcinoma had smoked for more years in total (median 38.5, range 4-54 years) than CLO patients (median 29.5, range 6-55 years $)(p<0 \cdot 01)$. Severe oesophagitis 
Figure 4: Average alcohol consumption in units/week.

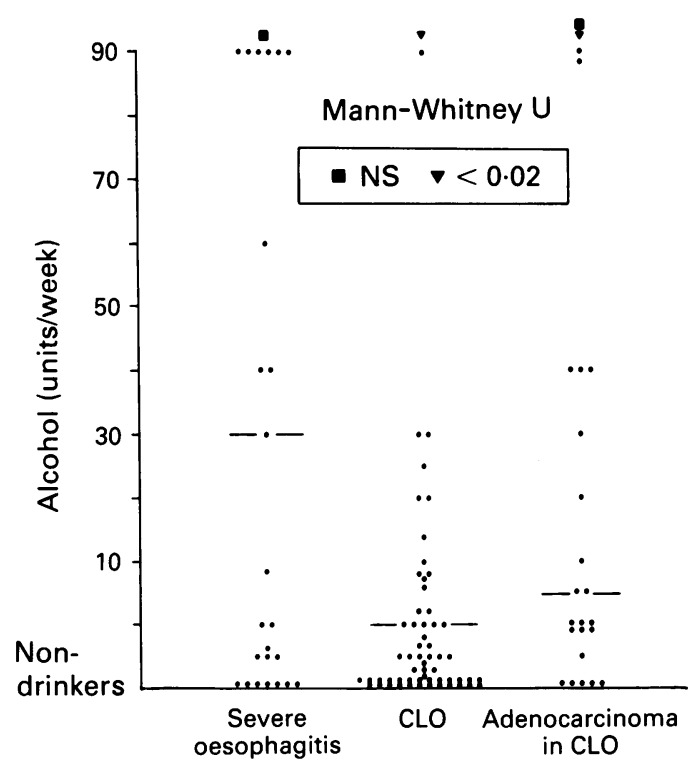

patients had a similar long history of smoking to adenocarcinoma patients (median $38 \cdot 5$, range 27-55 years); again much greater than CLO patients $(\mathrm{p}<0.003)($ Fig 3$)$.

CLO patients who smoked started at a slightly later age (median 20, range 12-38) than patients with severe reflux oesophagitis (median 18, range 10-28), and adenocarcinoma patients (median 18, range 14-25) $(\mathrm{p}<0 \cdot 02)$.

\section{ALCOHOL HISTORY}

A significantly greater proportion of CLO (23 of 58) patients were non-drinkers than severe reflux oesophagitis (4 of 23) and adenocarcinoma patients $(5$ of 24$)(\mathrm{p}<0.02)$. Of those patients who drank alcohol, half of the severe oesophagitis group drank more than 40 units/week and six drank more than 100 units/week (mean 50.2,

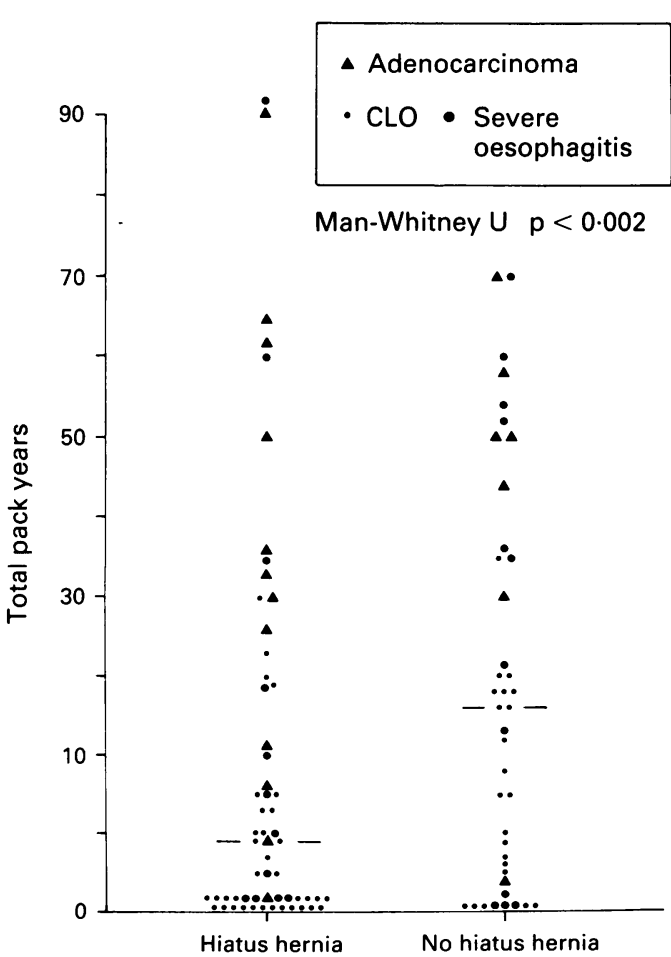

median 40, range 1->100 units/week). CLO patients who drank did so more moderately (mean 15.3, median 10, range 1-100 units/week) $(\mathrm{p}<0.01)$. Adenocarcinoma patients also had a significantly greater alcohol intake than CLO patients and two drank more than 100 units per week (mean $24 \cdot 7$, median 15 , range 1-100 units/ week $)(\mathrm{p}<0.02)($ Fig 4$)$.

\section{ROLE OF GENDER}

In order to exclude a bias as a result of a higher proportion of men being included in the adenocarcinoma group the data were analysed again for male patients only who smoked or drank. All male adenocarcinoma patients had smoked with a median value of 46 pack years (mean 55 pack years, range 4-200). Eleven of 36 male CLO patients had never smoked and of those who had smoked the median pack years accumulated was 15 (mean $20 \cdot 3$, range 5-60 pack years). Four of 19 male severe reflux oesophagitis patients had never smoked; for those who had smoked, values were median 62 pack years, mean 55, range 5-150 pack years. CLO had significantly more non-smokers; those who had smoked did so more lightly than the severe reflux oesophagitis or adenocarcinoma groups $(p<0.001)$. Nine of $36 \mathrm{CLO}$, three of 19 severe reflux oesophagitis, and three of 21 adenocarcinoma patients did not drink. Median alcohol consumption of those who drank was 11 units in CLO patients, which was less than the 50 units $(\mathrm{p}<0.001)$ in severe reflux oesophagitis patients. Excluding nondrinkers CLO alcohol consumption was no different from the adenocarcinoma group $(12 \cdot 5$ units/week).

\section{ROLE OF HIATUS HERNIA}

The total study population (104 patients with complicated gastro-oesophageal reflux disease)

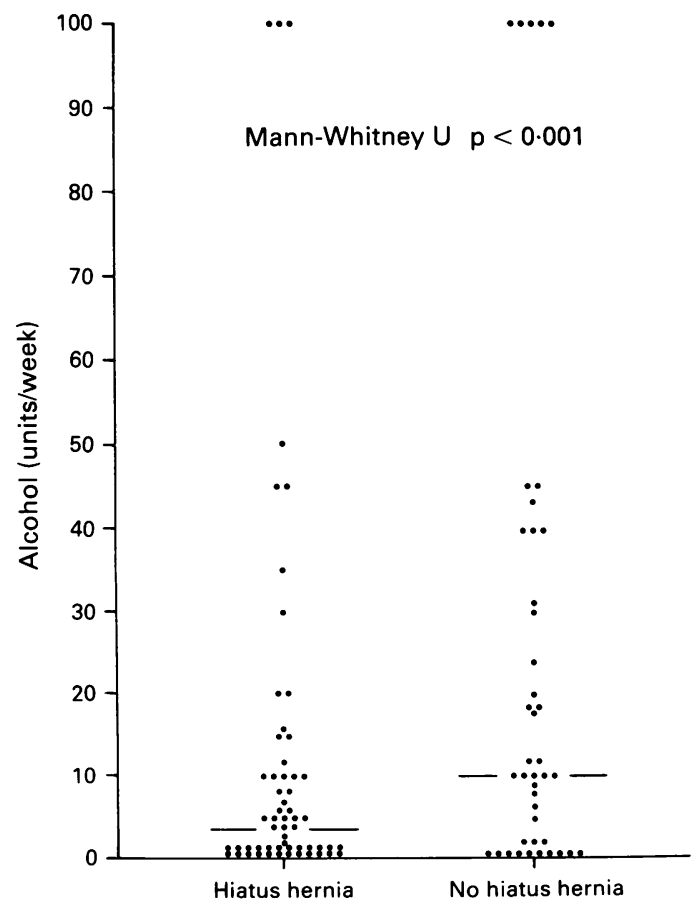

Figure 6: Alcohol consumption (units/week) in the presence or absence of a hiatus hernia. 
was subdivided into those with hiatus hernia and those without hiatus hernias. Those without hiatus hernias had heavier smoking histories overall (median 26 pack years) than those with hiatus hernias (median 9 pack years) $(\mathrm{p}<0.002)$ (Fig 5). The alcohol intake of patients without hiatus hernia was also greater than those with hiatus hernias (median $10 v 4$ units/week) $(\mathrm{p}<0.001)($ Fig 6) .

\section{Discussion}

The association of Barrett's columnar lined oesophagus (CLO) ${ }^{125}$ with gastro-oesophageal reflux has been well established ${ }^{2627}$ and the causative nature of ulceration followed by prolonged acid exposure has been shown in the dog model..$^{12}$ The degree of acid reflux in association with CLO is greater than that seen in patients with reflux oesophagitis as a whole..$^{28-30}$ Lower oesophageal sphincter pressure, number and duration of reflux episodes of less than $\mathrm{pH} 4$ and total duration of reflux episodes, however, is similar in CLO to patients with severe reflux oesophagitis without columnar metaplasia. ${ }^{29}{ }^{30}$ For this reason an additional agent has been hypothesised in the pathogenesis of CLO. The main contender, bile reflux, has been excluded by both clinical and experimental studies, ${ }^{12} 3132$ although bile reflux may be linked to stricture formation in patients with CLO. ${ }^{33}$ We have shown that patients with CLO have low concentration and production of salivary epiderma growth factor compared with normal controls and patients with severe reflux oesophagitis. ${ }^{34}$ Epidermal growth factor is cytoprotective in the upper gastrointestinal tract ${ }^{35}{ }^{37}$ and the inability to resist and heal ulceration may be a factor influencing development of CLO in patients with severe gastro-oesophageal reflux.

This study seems to refute the hypothesis that CLO is an end stage disease occurring in old patients ${ }^{38}$ with longer histories of reflux ${ }^{2}$ because of age, sex ratio, and duration of symptoms is similar to the severe reflux oesophagitis group. Although our sample may not be rigorously representative of the whole population with complications of reflux it is representative of the population presenting to physicians and surgeons with a gastroenterological interest.

The CLO study group included a greater proportion of non-smokers and non-drinkers than the severe reflux oesophagitis group, strong evidence against smoking and alcohol as pathogenic factors for CLO. CLO patients who did smoke started to smoke at a slightly later age, smoked for fewer years, and accumulated fewer pack years of smoking than the severe reflux oesophagitis group. This supports the finding of Robertson et al who saw no difference between the smoking and drinking habits of their CLO group and controls drawn from an orthopaedic clinic. ${ }^{39}$ This also supports the hypothesis that smoking and alcohol are not risk factors for development of CLO in patients with severe gastro-oesophageal reflux.

Patient sex does not seem to be an independent variable and exclusion of women from the analysis did not affect the differences seen between the groups. Two of three women with adenocarci- noma had accumulated more than 45 pack years each and one was also a heavy drinker. As with other respiratory and upper gastrointestinal tumours the male predominance seen is probably a result of the heavy smoking and drinking habits of men compared with women. ${ }^{40}$ Interestingly 20 of 23 severe oesophagitis patients smoked or drank heavily and of those who claimed no such history one had scleroderma and another may not have disclosed full details. Previous gastric surgery was not a feature of our tumour group as has been suggested by previous studies.

The prolonged oesophageal acid exposure seen in patients with hiatus hernia is due to reduced acid clearance but it is only seen in patients with lower oesophageal sphincter deficiency. ${ }^{41}$ Our results suggest a link between smoking and alcohol and complications (CLO, severe oesophagitis, or adenocarcinoma) of acid reflux in patients without hiatus hernias. Smoking and alcohol may promote the reflux inflammation lower oesophageal sphincter dysfunction cycle in those without a hiatus hernia.

Ninety five per cent of those patients who developed adenocarcinoma in CLO smoked and half of them drank more than 40 units of alcohol per week representing a subgroup of patients with metaplastic CLO at increased risk. Patients with adenocarcinoma had smoking and drinking histories similar to those patients with severe oesophagitis. This implies that, while development of CLO in itself is independent of smoking and alcohol, a combination of CLO and excessive smoking is required for the initiation and promotion of adenocarcinoma of the oesophagus.

In animal models of oesophageal carcinogenesis, gastro-oesophageal reflux promotes tumour development ${ }^{42}$ but reflux alone does not cause tumour formation in the absence of a carcinogen. ${ }^{43}$ Increased proliferative activity in gastrointestinal epithelium promotes tumour formation $^{445}$ and inhibition of proliferation reduces tumour incidence. ${ }^{46}$

Adenocarcinoma and dysplasia are frequently associated with the specialised type $\mathrm{CLO}^{46-48}$ and dysplasia and carcinoma are thought to arise within specialised type CLO. ${ }^{48}$ The specialised histological type is associated with a higher rate of cell turnover as shown by thymidine labelling $^{49} 50$ and a higher proportion of cells in cycle (by proliferating cell nuclear antigen immunolocalisation) than junctional and fundic types. ${ }^{5152}$ Accelerated proliferation increases the likelihood of exposure of cellular genetic material to mutagenic stimuli which can cause the genomic instability that precedes the development of malignancy..$^{53}$ Our hypothesis is that specialised type CLO predisposes to the development of adenocarcinoma of the oesophagus because of increased proliferative activity and that tumour development occurs in patients exposed to an environmental carcinogen most commonly ingested in cigarette smoke.

Prospective screening of populations with known CLO require 52 to 440 patient years of follow up to detect one adenocarcinoma. ${ }^{139}$ Most adenocarcinomas of the oesophagus, however, arise in CLO that is already established ${ }^{+8}$ and the disparity between incidence and prevalence can be accounted for by the high proportion 
of the population with unrecognised disease, up to 20 times that of those detected. ${ }^{54}$ It is necessary to identify a subpopulation of patients with CLO who are at especially high risk of developing adenocarcinoma so that a screening protocol that is cost effective and has an impact on patient survival can be developed.

Smoking does not predispose to the development of CLO in patients with severe gastrooesophageal reflux. The middle aged or elderly patient who presents with CLO and a heavy smoking history, however, is already at increased risk of developing adenocarcinoma, a risk not reversed by anti-reflux surgery. ${ }^{55}$ Smokers and ex-smokers make up a subgroup at increased risk for development of adenocarcinoma in Barrett's oesophagus; those patients with specialised type metaplasia and who may benefit from surgical intervention warrant regular endoscopy and biopsy whereas nonsmokers are at low risk.

MRG is supported by the North West Cancer Research Fund.

1 Barrett NR. The lower oesophagus lined by columnar epithelium. Surgery 1957; 41: 881-94.

2 Gray MR. Barrett's oesophagus and ulcerative complications of reflux oesophagitis. Gullet 1993; 3 (suppl 1): 42-52.

3 Sarr MG, Hamilton SR, Marrone GC, Cameron JL. Barrett's esophagus: its prevalence and association with adenocarcinoma in patients with symptoms of gastroesophageal reflux. Am f Surg 1985; 149: 187-93.

4 Winters C, Spurling TJ, Chobanian SJ, Curtis DJ, Esposito $\mathrm{RL}$, Hacker JF, et al. Barrett's esophagus: a prevalent ocult complication of gastro-esophageal reflux disease. Gastroenterology 1987; 92: 118-24.

5 Hameeteman W, Tytgat GNJ, Houthoff $\mathrm{HJ}$, van den Tweel JG. Barrett's esophagus: development of dysplasia and JG. Barrett's esophagus: development of dysplas

6 Hesketh PJ, Clapp RW, Doos WG, Spechler SJ. The increasing frequency of adenocarcinoma of the oesophagus. Cancer 1989; 64: 526-30.

7 Alpern HD. Increasing percentage of adenocarcinoma primary carcinoma of the esophagus. Am $\mathcal{f}$ Gastroenterol 1989; 84: 574 .

8 Doll R, Peto R. Mortality in relation to smoking: 20 years observations on male British doctors. BMF 1976; 2: 152536.

9 Skinner DB, Walther BC, Riddell RH, Schmidt H, Iascone C, DeMeester TR. Barrett's esophagus: comparison of benign and malignant cases. Ann Surg 1983; 198: 554-66.

10 Logan RFA, Riddick A. Barretts oesophagus - are smoking and drinking risk factors. Gut 1990; 31: A603.

11 Spechler SJ, Robbins AH, Rubins HB, et al. Adenocarcinoma and Barrett's esophagus: an overrated risk? Gastroenterology 1984; 87: 927-33.

12 Bremner CG, Lynch VP, Ellis EH. Barretts oesophagus: congenital or acquired? An experimental study of oesophageal mucosal regeneration in the dog. Surgery 1970; 68: 209 16.

13 Gillen P, Keeling P, Byrne PJ, Healy M, West AB, Hennessy TPJ. Experimental columnar metaplasia in the canine oesophagus. Brf Surg 1988; 75: 540-3.

14 Chattopadhyay DK, Greaney MG, Irving TT. Effect of cigarette smoking in the lower oesophageal sphincter. $G u t$ 1977; 18: 833-5.

15 Dennis SW, Castell DO. Inhibitory effect of smoking on the lower esophageal sphincter. $N$ Engl $f$ Med 1971; 284: 1136-7.

16 Rattan S, Goyal RK. Effect of nicotine on the lower esophageal sphincter. Gastroenterology 1975; 69: 154-9.

17 Stanciu C, Bennett JR. Smoking and gastro-oesophagea reflux. $B M \mathcal{F} 1972 ; 3: 793-5$

$18 \mathrm{Kjellin} \mathrm{G}$, Tibbling $\mathrm{L}$. Influence of body position, dry and water swallows, smoking and alcohol on esophageal acid clearing. Scand $\mathcal{F}$ Gastroenterol 1978; 13: 283-8.

19 Whitecross DP, Clarke AD, Piper DW. The effect of cigarette smoking on human gastric secretion. Scand $\mathcal{F}$ Gastroenterol 1974; 9: 399-403.

20 Read NW, Grech P. Effect of cigarette smoking on competence of the pylorus: preliminary study. $B M F 1973 ; 3: 313-6$.

21 Begemann F, Schwoy M, Schumpelick V. Zigarettenrauchen und duodenogastraler reflux. Innere Medizin 1980; 7: 165-8.

22 Orlando RC, Bryson JC, Powek DW. Effect of cigarette smoke on esophageal epithelium of the rabbit. Gastroenterolog

23 Jones PDE, Hudson N, Hawkey C. Depression of salivary epidermal growth factor by smoking. Gut 1991; 22: A556.

24 Koelz HR, Birchler R, Bretholz A, Bron B, Capitaine Y Delmore $\mathrm{G}$, et al. Healing and relapse of reflux esophagitis during treatment with ranitidine. Gastroenterology 1986; 91 1198-205.

25 Barrett NR. Chronic peptic ulcer of the oesophagus and oesophagitis. Br J Surg 1950; 38: 175-82.
26 Hamilton SR. Pathogenesis of columnar cell-lined (Barrett) esophagus. In: Spechler SJ, Goyal RK, eds. Barrett's oesophagus: pathophys, diagnosis and management. New York Elsevier, 1985: 29-37.

27 Isacone C, DeMeester TR, Little AG, Skinner DB. Barrett's oesophagus: functional assessment, proposed pathogenesis and surgical therapy. Arch Surg 1983; 118: 543-9.

28 Flook D, Stoddard CJ. Gastro-oesophageal reflux (GOR) in patients with oesophagitis or a columnar lined (Barrett's) patients with oesophagitis or a cop
oesophagus. Gut 1983; 24: A1007.

29 Gillen P, Keeling P, Byrne PJ, Hennessy TPJ. Barrett's oesophagus: pH profile. BrF S Surg 1987; 74: 774-6.

30 Parrilla P, Ortiz A, de Haro LFM, Aguayo JL, Ramirez P. Evaluation of the magnitude of gastro-oesophageal reflux in Barrett's oesophagus. Gut 1990; 31: 964-7

31 Gillen P, Keeling P, Byrne PJ, Healy M, O'Moore RR, Hennessy TPJ. Implications of duodenogastric reflux in the pathogenesis of Barrett's oesophagus. Br $\mathcal{F}$ Surg 1988; 75; $540-3$.

32 Attwood SEA, DeMeester TR, Bremmner CG, Barlow AP Hinder RA. Alkaline gastroesophageal reflux: implications in the development of complications in Barrett's columnarin the development of complications in Barrett's
lined lower esophagus. Surgery 1989; 106: 764-70.

33 DeMeester TR, Attwood SEA, Smyrk TC, Therkildsen DH Hinder RA. Surgical therapy for Barretts esophagus. Ann Surg 1990; 212: 528-42.

34 Gray MR, Donnelly R, Kingsnorth AN. Role of salivary epidermal growth factor in the pathogenesis of Barrett's columnar line oesophagus. Brf Surg 1991; 78: 1461-6.

35 Gray MR, Kingsnorth AN. The role of salivary epiderma growth factor and transforming growth factor alpha in the pathogenesis of Barrett's columnar lined oesophagus. Eur Surg Res 1991; 23 (suppl 1): A103.

36 Konturek SJ, Radecki T, Brzozowski T, Piastucki I. Gastric cytoprotection by epidermal growth factor: role of endocytoprotection by epidermal growth factor: role of endogenous prostoglandin

37 Tepperman BL, Soper BD, Morris GP. Effect of sialoadenectomy on adaptive cytoprotection in the rat. Gastroenterology 1989; 97: 123 .

38 Khoury GA, Bolton. Age: an important factor in Barrett's oesophagus. Ann Royal Coll Surg 1989; 71: 50-3.

39 Robertson CS, Mayberry JR, Nicholson DA, James PD Atkinson $M$. Value of endoscopic surveillance in the detection of neoplastic change in Barrett's oesophagus. Br F Surg 1988; 75: 760-3.

40 Flamant R, Lassere O, Lazer R, LeGuerinais J, Denoix P, Schwartz D. Differences in sex ratio according to cancer site and possible relationship with use of tobacco and alcohol. Review of 65000 cases. $\mathcal{f}$ Natl Cancer Inst 1965; 32: 1304 .

41 DeMeester TR, LaFontaine E, Joelsson BE, Skinner DB Ryan JW, O'Sullivan GC, et al. The relationship of a hiatus hernia to the function of the body of the oesophagus and the gastro-oesophageal junction. $\mathcal{F}$ Thorac Cardiovasc Surg 1981; 82: 547-58.

42 Pera M, Cardesa A, Bombi JA, Ernst H, Pera C, Mohr V. Influence of oesophagojejunostomy on the induction of adenocarcinomas of the distal oesophagus in sprague-dawley rats by subcutanous injection of 26 dimethylnitrosomorpholine. Cancer Res 1989; 49: 6830-8.

43 Terpstra OT, Dahl EP, Williamson RCN, Ross JS, Malt RA. Colostmy closure promotes cell proliferation and dimethylhydrazine-induced carcinogenesis in rat distal colon. Gastroenterology 1981; 81: 475-80.

44 Rainey JB, Davies PW, Bristol JB, Williamson RCN. Adaptation and carcinogenesis in defunctioned rat colon: divergen tion and carcinogenesis in defunctioned rat colon: divergent effects of

45 Kingsnorth AN, Russell WE, McCann PP, Diekema KA Ross JS, Malt RA. Inhibition of ornithine decarboxylase with alpha-diflouromethylornithine: reduced incidence of dimethylhydrazine-induced colon tumors in mice. Cancer Res 1983; 43: 2545-9.

46 Paull A, Trier JS, Dalton MD, Camp RC, Loeb P, Goyal RK. The histologic spectrum of Barrett's esophagus. $N$ Engl f Med 1976; 295: 477-80.

47 Jass JR. Mucin histochemistry of the columnar epithelium of the oesophagus: a retrospective study. $\mathcal{F}$ Clin Pathol 1981 ; 34: 866-70.

48 Hamilton SR, Smith RL. The relationship between columnar epithelial dysplasia and invasive adenocarcinoma arising in Barrett's esophagus. Am F Clin Pathol 1987; 87: 301-12.

49 Herbst JJ, Berenson MM, McClosky DW, Wiser WC. Cel proliferation in esophageal columnar epithelium (Barrett's esophagus). Gastroenterology 1978; 75: 683-7.

50 Pellish LJ, Heimos JA, Eastwood GL. Cell proliferation in three types of Barrett's epithelium. Gut 1980; $21: 26-31$.

51 Gray MR, Hall PA, Lane D, Ansari B, Nash J, Kingsnorth AN. Epithelial proliferation in Barrett's esophagus: by 1769-76.

52 Gray MR, Wallace HM, Goulding H, Hoffmann J, Kenyon WE, Kingsnorth AN. Mucosal polyamine metabolism in the columnar lined oesophagus. Gut 1993; 34: 584-7.

53 Rabinovitch PS, Reid BJ, Haggit RC, Norwood TH, Rubin CE. Progression to cancer in Barrett's esophagus is associCE. Progression to cancer in Barrett's esophagus is associ-
ated with genomic instability. Lab Invest 1988; 60: 65-71.

54 ated with genomic instability. Lab Invest 1988; 60: 65-71. Cameron AJ, Zinsmeister AR, Ballared DJ, Carney JA.
Prevelence of columnar-lined (Barrett's) esophagus: comPrevelence of columnar-lined (Barrett's) esophagus: com-
parisons of population-based clinical and autopsy findings. parisons of population-based clinical

55 Hamilton SR, Hutcheon DF, Ravich WJ, Cameron JL, Poulson $M$. Adenocarcinoma in Barrett's oesophagus after elimination of gastro-oesophageal reflux. Gastroenterolog 1984; 86: 356-60. 